\title{
ESTRATÉGIAS GERENCIAIS PARA O DESENVOLVIMENTO DE COMPETÊNCIAS EM ENFERMAGEM EM HOSPITAL DE ENSINO
}

\author{
Louise Bueno Lelli ${ }^{1}$, Elizabeth Bernardino², Aida Maris Peres ${ }^{2}$, Luciana Aparecida Fabriz $^{3}$
}

RESUMO: Estudo de abordagem qualitativa buscou identificar as competências gerenciais utilizadas por enfermeiros que ocupam cargo de supervisores em unidades funcionais assistenciais, em um hospital de ensino na capital paranaense; levantar as competências esperadas pelos enfermeiros sob sua responsabilidade e apreender qual a sua contribuição para o desenvolvimento dessas competências. A amostra se constituiu de 8 enfermeiros. A coleta de dados foi realizada em setembro de 2010 mediante entrevista semiestruturada associada à vinheta, análise temática foi utilizada para a compreensão dos discursos. As categorias encontradas foram trabalho em equipe, comunicação, planejamento, administração de conflitos, liderança, relacionamento interpessoal, técnica, tomada de decisão, compromisso, motivação, facilidades para o desenvolvimento pessoal e profissional. Verificou-se que as competências gerenciais identificadas são tradicionais e não confluentes com o modelo institucional, contudo, as estratégias para o desenvolvimento de competências necessitam ser reavaliadas e inovadas visando resultados positivos e consolidados.

PALAVRAS-CHAVE: Enfermagem; Administração; Competência profissional.

\section{MANAGERIAL STRATEGIES FOR DEVELOPING COMPETENCIES IN NURSING IN A TEACHING HOSPITAL}

ABSTRACT: This study with a qualitative approach aimed to identify the managerial competencies used by nurses who occupy the role of supervisors in units which provide hands-on care, in a teaching hospital in the capital of the state of Paraná; highlighting the competencies expected by the nurses under their responsibility and learning what their contribution should be for the development of these competencies. The sample was made up of 8 nurses. Data collection took place in September 2010 through semi-structured interviews associated with vignettes. Thematic analysis was used for understanding the discourses. The categories found were: team work, communication, planning, administration of conflicts, leadership, interpersonal relationships, technique, decision-making, commitment, motivation, and facilities for personal and professional development. It was ascertained that the managerial competencies identified are traditional and not confluent with the institutional model, however, the strategies for developing the competencies need to be re-evaluated and updated with a view to positive and consolidated results.

KEYWORDS: Nursing; Administration; Professional competency.

\section{ESTRATEGIAS ADMINISTRATIVAS PARA EL DESARROLLO DE COMPETENCIAS EN ENFERMERÍA EN HOSPITAL DE ENSEÑANZA}

RESUMEN: Estudio de abordaje cualitativa que ha buscado identificar las competencias administrativas utilizadas por enfermeros que ocupan cargo de supervisores en unidades funcionales asistenciales, en un hospital de enseñanza en la capital de Paraná; levantar las competencias esperadas por los enfermeros bajo su responsabilidad y aprender cuál es su propia contribución para el desarrollo de esas competencias. La muestra se constituyó de 8 enfermeros. Los datos fueron recogidos en septiembre de 2010 por medio de entrevista semi estructurada asociada a viñeta; análisis temático fue utilizado para comprensión de los discursos. Las categorías fueron trabajo en equipo, comunicación, planeamiento, administración de conflictos, liderazgo, relación interpersonal, técnica, decisión, compromiso, motivación, facilidades para el desarrollo personal y profesional. Se ha verificado que las competencias administrativas identificadas son tradicionales y no confluentes con el modelo institucional, sin embargo, las estrategias para el desarrollo de competencias necesitan ser de nuevo evaluadas e innovadas para obtener resultados positivos y consolidados.

PALABRAS CLAVE: Enfermería; Administración; Competencia profesional.

\footnotetext{
${ }^{1}$ Enfermeira Residente do Programa de Residência Multiprofissional do Hospital Erasto Gaertner - Curitiba-PR.

${ }^{2}$ Enfermeira. Doutora em Enfermagem. Professora do Departamento de Enfermagem e do Programa de Pós-Graduação em Enfermagem da Universidade Federal do Paraná - PPGENF UFPR. Membro do Grupo de Pesquisas em Políticas, Gestão e Prática em Saúde - GPPGPS. ${ }^{3}$ Enfermeira. Diretora de Enfermagem do Hospital Universitário do Oeste do Paraná. Mestranda pelo PPGENF UFPR. Membro do GPPGPS.
}

Autor correspondente:

Luciana Aparecida Fabriz

Universidade Federal do Paraná

Rua Rio de Janeiro,686 - 85801-030 -Cascavel-PR-Brasil

Email: luciana.fabriz@gmail.com
Recebido: 05/11/2011

Aprovado: 01/05/2012

Cogitare Enferm. 2012 Abr/Jun; 17(2):262-9 


\section{INTRODUÇÃO}

O gerenciamento em enfermagem, nas instituições hospitalares, é atividade complexa, visto que existe uma exigência cada vez maior, direcionada aos profissionais para que exerçam competências cognitivas, técnicas e atitudinais na implementação de estratégias adequadas às atuais tendências administrativas ${ }^{(1)}$.

E para que o enfermeiro gerente se adapte a este novo modelo imposto pelas mudanças decorrentes do mundo globalizado é necessária uma reformulação no modelo gerencial proposto no Brasil pelo Sistema Único de Saúde. A mobilização de competências é uma das estratégias, sendo necessário, para tanto, conhecimento habilidade e atitude ${ }^{(2)}$.

A delimitação do perfil gerencial dos enfermeiros é relevante e pertinente, pois subsidia a adoção de estratégias para a capacitação dos mesmos; e o desenvolvimento de competências gerenciais constitui elemento chave na solução dos problemas existentes nas instituições de saúde ${ }^{(3)}$.

Um hospital de ensino do Município de Curitiba-PR adotou, em 2002, um modelo gerencial, democrático e participativo, baseado na descentralização das decisões e na co-responsabilização do corpo funcional ${ }^{(4)}$. O referido hospital foi reorganizado em unidades gerenciais, que se classificam em administrativas e assistenciais. Estas últimas correspondem ao agrupamento de unidades afins, que formam uma linha de cuidado e possuem, para sua administração, um supervisor médico, um supervisor administrativo e um supervisor de enfermagem. Neste cenário, o enfermeiro supervisor tem sob sua responsabilidade a assistência de enfermagem deste grupo de unidades, e faz uso de competências gerenciais para exercê-la.

Este estudo buscou identificar as competências gerenciais utilizadas por enfermeiros que ocupam cargo de supervisores em unidades funcionais gerenciais assistenciais em um hospital de ensino no município de Curitiba - Paraná, as competências esperadas pelos enfermeiros sob sua responsabilidade e sua contribuição para o desenvolvimento destas.

\section{MÉTODO}

Trata-se de uma pesquisa de abordagem qualitativa. Para a coleta de dados, foi realizada uma entrevista com enfermeiros supervisores de enfermagem das unidades funcionais gerenciais assistenciais. Utilizou- se entrevista semiestruturada como instrumento de coleta de dados, por ser um processo de interação entre duas pessoas, onde o entrevistador busca a obtenção de informações por parte do outro, o entrevistado ${ }^{(5)}$.

A população da pesquisa estimada era de 10 enfermeiros supervisores de Unidades Gerenciais Assistenciais determinadas pelo número total de unidades do hospital. Participaram da pesquisa 8 enfermeiros, tendo em vista que um estava de férias e outro não teve disponibilidade de horários, mesmo após sucessivos contatos.

Foram 9 unidades funcionais assistenciais que compuseram a pesquisa: Urgência e Emergência, Ambulatórios, Cardiovascular e Pneumologia, Diagnóstico por Imagem e Terapia por Radiações, Centro Cirúrgico, Mulher e Recém-Nascido, Neurologia, Hemato-Oncologia e Oftalmologia.

Os critérios de inclusão dos enfermeiros foram: ser supervisor de enfermagem de uma unidade funcional assistencial. Os critérios de exclusão foram o sujeito se recusar a participar da pesquisa, estar de férias ou de licença. O projeto foi aprovado pelo Comitê de Ética em Pesquisa sob n. 2271.165/2010-07.

As entrevistas aconteceram no mês de setembro de 2010. Para facilitar a compreensão dos entrevistados sobre definição de competência, foi utilizada uma vinheta como estratégia de coleta de dados. A vinheta é conceituada como sendo uma descrição breve de eventos, ou situações às quais os respondentes são solicitados a reagir ${ }^{(6)}$.

As entrevistas foram gravadas e a transcrição das falas dos sujeitos foi analisada, na modalidade de análise temática ${ }^{(7)}$, que busca agrupar semelhanças, recorrências e sentidos em núcleos de sentido, que a seguir permitem enumerar as unidades de significado e estas, por sua vez, definem as categorias temáticas.

\section{RESULTADOS}

Na caracterização dos sujeitos observou-se que $100 \%$ são do sexo feminino; a média de idade era de 49,8 anos; de formação de 19,5 anos, 37,7\% possuíam especialização em gerenciamento e $62,3 \%$ não a possuíam e a média de tempo que ocupavam estes cargos era de 21,8 meses.

Após o tratamento dos dados das entrevistas, as categorias temáticas que emergiram das falas, foram relacionadas aos objetivos da pesquisa e estão descritas no quadro 1. Os recortes dos discursos estão apresentados juntamente com a discussão. 
Quadro 1 - Relação entre objetivos e categorias temáticas. Curitiba, 2010

\begin{tabular}{|l|l|}
\hline \multicolumn{1}{|c|}{ OBJETIVOS } & \multicolumn{1}{|c|}{ CATEGORIAS TEMÁTICAS } \\
\hline $\begin{array}{l}\text { Competências gerenciais utilizadas por } \\
\text { enfermeiros que ocupam cargo de super- } \\
\text { visores em unidade gerencial assistencial }\end{array}$ & $\begin{array}{l}\text { Trabalho em equipe } \\
\text { Comunicação } \\
\text { Planejamento } \\
\text { Administração de conflitos } \\
\text { Liderança }\end{array}$ \\
\hline $\begin{array}{l}\text { Competências que as supervisoras esperam } \\
\text { dos enfermeiros sob sua responsabilidade }\end{array}$ & $\begin{array}{l}\text { Relacionamento interpessoal } \\
\text { Liderança }\end{array}$ \\
Competência técnica \\
Tomada de decisão \\
Compromisso
\end{tabular}

\section{DISCUSSÃO}

Observa-se que a média de idade dos sujeitos é alta, 49,8 anos, bem como o tempo de formação (19,5 anos). Atribuímos estes resultados ao fato de o Hospital existir há mais de 50 anos e as características de hospitais públicos, em que a forma de contratação nestas instituições, em sua maioria, ocorre por concurso público em regime estatutário.

A idade avançada dos servidores de enfermagem em hospitais públicos e de ensino é um dado preocupante para os enfermeiros gerentes, tendo em vista que esta é uma população significativa nestes hospitais, as quais, em sua maioria, não podem ser contadas como mão de obra operante, devido a problemas de limitações físicas decorrentes da profissão. Contudo, estas informações não são consideradas em solicitações de novos servidores.

Em relação à formação dos enfermeiros, o número de sujeitos que não possui uma formação específica para o cargo de gerência foi superior ao número de supervisores que detém tal formação. Com isto, pode-se afirmar que a formação gerencial não é pré-requisito para assumir um cargo de gerência nesta instituição, sendo a experiência profissional o fator de escolha.

Neste contexto, a qualificação profissional necessária ao enfermeiro gerente pode ser compreendida como o conhecimento para desempenhar estas atribuições. Esse permite sustentação teórica propiciando autonomia e reconhecimento, porém para que o enfermeiro seja competente como gerente deve somar ao conhecimento a habilidade de se fazer corretamente e que se tenha atitude adequada visando bons resultados ${ }^{(2)}$.
As categorias temáticas extraídas dos discursos foram o trabalho em equipe, a comunicação, o planejamento, a administração de conflitos, a liderança em dois aspectos distintos, o relacionamento interpessoal, a técnica, a tomada de decisão, compromisso e motivação e facilidades para o desenvolvimento pessoal e profissional.

O trabalho em equipe esteve presente nas falas e foi relacionado à equipe de enfermagem e à equipe multiprofissional. Pode-se notar a importância do trabalho em equipe na seguinte afirmação:

Porque a essência dessa prática de unidade gerencial é trabalhar com o problema quando trazido [...]. Discutido e junto com o grupo se procurar a solução [...]. Dentro de um modelo como esse de unidade funcional, tem que se trabalhar com a equipe multiprofissional [...]. A gente termina se valendo da vivência, do trabalho articulado. Mas, com os outros profissionais. Não se trabalha mais sozinho. (S2)

A articulação multiprofissional é caracterizada por relações de interdependência e de complementaridade, em que o supervisor passa a ser um elemento importante na gestão e organização do trabalho em saúde. $\mathrm{O}$ trabalho em equipe como competência utilizada por este tipo de supervisor insere-se no processo de consolidação do trabalho( ${ }^{(8)}$.

$\mathrm{O}$ modelo gerencial de unidade funcional tem como uma das estratégias o trabalho em equipe da enfermagem e dos demais profissionais de saúde. Este fato é notado quando, na fala da enfermeira supervisora é apresentada a situação de que o grupo discute em busca de soluções. 
A categoria comunicação emergiu das falas das supervisoras de enfermagem das unidades funcionais assistenciais em questão. Percebe-se nos discursos a utilização da comunicação como competência:

Então se valendo de articulação, se valendo da parceria, se valendo do ouvir e do falar [...]. Mais ouvir do que falar. (S2)

Das minhas atividades que mais demandam tempo é este diálogo, essa conversa [...]. (S7)

Tem que ter respeito pelas pessoas e tem que saber falar [...]. (S6)

A comunicação é uma estratégia necessária ao enfermeiro - líder, a qual permite o entendimento das informações, podendo acontecer de forma verbal ou não verbal, sendo um meio para a interação entre as pessoas e troca de opiniões ${ }^{(9)}$.

Sob o ponto de vista das entrevistadas, para a comunicação acontecer deve-se considerar o saber ouvir, saber o que falar e como falar. O desenvolvimento desta competência demanda tempo e comunicar-se adequadamente facilita que o trabalho da unidade flua de acordo com as suas expectativas.

O planejamento é uma competência relevante no trabalho do enfermeiro supervisor, como pode ser notado nos discursos das enfermeiras entrevistadas:

Ao oportunizar para que cada um dos serviços que compõem a unidade possa desempenhar suas tarefas [...]. Os seus trabalhos com material, com equipamento e com recursos humanos suficientes pra que realmente eles possam trabalhar. (S2)

A gente organiza, faz um planejamento, cria estratégias. Criamos metas, objetivos [...]. (S3)

Os profissionais devem estar preparados para tomar iniciativa, o gerenciamento e a administração da força de trabalho, recursos físicos e materiais e de informação ${ }^{(10)}$. Não obstante, ter sido observado que a competência planejamento é utilizada no desempenho das funções gerenciais da enfermeira supervisora. O planejamento da assistência não foi evidenciado, embora muitas referirem a importância de uma assistência de qualidade.

A administração de conflitos mostrou-se uma competência relevante nos relatos das entrevistadas, como se evidencia na locução que demonstra que saber administrar conflitos é, de fato, uma competência utilizada pelas profissionais em questão:

Então eu acho que eu fico mais na articulação mesmo [...]. Existe mais um jogo de cintura [...]. Como eu digo, eu acho que sou mais mediadora de conflitos [...]. Mas, além disso, a gente sempre que pode tenta resolver os problemas de todos. (S3)

Certos padrões de conflitos são intrínsecos às organizações hospitalares, pois expressam relações de poder e status social. Os hospitais são espaços sociais conflituosos por natureza e nas instituições de saúde, a gama de diferentes categorias profissionais, aliada à hierarquização do poder, característica de organizações com muitas especialidades profissionais, torna mais difícil o trabalho ${ }^{(11)}$.

Ao administrar o conflito, o enfermeiro e sua equipe devem identificar o problema, analisar sua origem e empregar esforços para eliminá-lo, minimizando seus efeitos e prevenindo futuras ocorrências ${ }^{(12)}$. As situações de conflitos requerem dos gerentes de enfermagem habilidades para identificar a causa destes comportamentos, e de posse destas informações, traçarem estratégias para solucionar os problemas encontrados.

A administração de conflitos é uma competência que não está desarticulada do trabalho em equipe, da comunicação, da coordenação da assistência. Esta articulação faz com que o enfermeiro torne-se uma referência entre os demais profissionais, para a resolução de conflitos e outras situações administrativas.

A liderança surgiu de forma significativa nas locuções dos sujeitos, como exemplificado nos discursos a seguir:

Como gerente o que a gente mais faz é liderar a equipe, manter a qualidade no trabalho, focar na eficácia, manter o nivel de satisfação do usuário, incentivar a equipe para buscar caminhos alternativos sem desviar da missão da instituição. (S8)

Nós temos que dar um direcionamento [...]. Então você tem que ter uma liderança [...]. Tem que atuar e fazer com que as coisas saiam a contento. (S6)

A liderança é das principais competências, estando as relações profissionais e pessoais caracterizadas pelas três bases estruturais da instituição da liderança: a organizacional, onde os gerentes procuram pessoas que se adaptam bem ao sistema e ao grupo, concentrando- 
se na produção mediante o exercício do poder e da autoridade; a libidinal, o líder tem a preocupação de promover sentimentos bons, aceitação entre colegas e subordinados; e a ideológica, visto que o líder é responsável por manter a coesão do grupo ${ }^{(13)}$.

Os relatos das enfermeiras expressam a importância da competência liderança na prática profissional, na organização, confiança e direcionamento da equipe de trabalho, confirmando os conceitos encontrados em literaturas.

Quanto ao questionamento sobre quais competências as supervisoras de enfermagem gostariam que os enfermeiros sob sua responsabilidade possuíssem, estas relataram a importância de competências como o relacionamento interpessoal, liderança, técnica e tomada de decisão.

A primeira competência desejada foi o relacionamento interpessoal. Apareceu nos discursos em três aspectos: com a equipe, com o paciente, e com o familiar. Esta competência pode ser exemplificada com a fala a seguir:

Em referência ao relacionamento interpessoal, pela questão bem grande de que existe conflito. Na questão tanto com o funcionário, quanto com o paciente e o familiar. (S6)

Quando se considera o relacionamento interpessoal com a equipe, a competência interpessoal é tida como necessária ao profissional na atualidade, visto que o habilita a lidar de forma eficaz no âmbito das relações interpessoais, diante das mais diversas situações. $\mathrm{O}$ aprimoramento da competência interpessoal dos enfermeiros gestores e supervisores podem facilitar as relações do dia a dia no contexto institucional, tornando suas atitudes mais efetivas ${ }^{(14)}$.

Nos serviços de saúde o enfermeiro é reconhecido como referência na organização, planejamento e garantia da assistência prestada aos pacientes, sendo, portanto, extremante necessário que estes profissionais mantenham um bom relacionamento interpessoal, visando a garantir de um trabalho harmonioso e de qualidade.

A liderança esteve presente no discurso das enfermeiras supervisoras como competência esperada para as enfermeiras subordinadas a elas, como mostrado no discurso a seguir:

\section{Liderança. Tem que existir mais liderança. (S2)}

Ter força de liderança, ser forte o suficiente e conseguir liderar a equipe. (S7)
No contexto das entrevistas realizadas pode-se perceber que a liderança como competência para estas gerentes é uma função dos enfermeiros, está relacionada com o fato de o mesmo ter a obrigação de liderar a sua equipe, a fim de se evitarem problemas para a instituição. Mais uma vez, esta liderança relaciona-se fortemente com uma atribuição instituída pelo cargo profissional, dentro da instituição hospitalar. Enquanto gerentes, elas esperam que as enfermeiras subordinadas a elas exerçam de fato a liderança, de modo a contribuir com seu trabalho e, concomitantemente, com a instituição.

A liderança, pode ser conceituada como uma habilidade em envolver a equipe de enfermagem para se atingir um objetivo e se coordenar o processo de trabalho ${ }^{(9)}$.

De acordo com as enfermeiras supervisoras a técnica e o conhecimento científico são requisitos necessários para os enfermeiros sob sua responsabilidade, como podemos observar nas falas abaixo:

Então é um pessoal bem ativo em relação ao conhecimento e a trazer pra nossa unidade mais conhecimento. (S3)

Mais conhecimento científico na hora da atuação. (S4)

O conhecimento é um instrumental ao trabalho dos enfermeiros e está incorporado à produção da assistência, da educação, da atividade gerencial e da pesquisa ${ }^{(15)}$.

Os depoentes enfatizam o conhecimento técnico para resolverem as questões da complexidade da assistência, necessárias à administração da prescrição médica e de enfermagem. Os enfermeiros entrevistados reconhecem que a experiência do cotidiano assistencial serve para construir a profissão e a autonomia do enfermeiro. Entendem a aquisição prática de conhecimentos como uma via de compreensão do processo assistencial e da construção de segurança do fazer do enfermeiro. A técnica, para estas gerentes, é um fator de importância enquanto competência a ser esperada, por parte das enfermeiras que compõem as equipes. Nota-se que esta competência está enraizada na função tradicional do profissional de enfermagem e espera-se que este seja competente tecnicamente, justificando uma assistência de qualidade.

A tomada de decisão apareceu nos discursos como categoria temática que reuniu as atitudes esperadas pelas gerentes, no que se refere à resolutividade de questões conflituosas: 
Que sejam pró-ativas nas atividades de sua competência, que mantenham sempre a capacidade de resolver as questões conflituosas que surgem na execução do trabalho. (S8)

O trabalho dos profissionais de saúde deve estar fundamentado na capacidade de tomar decisões, visando o uso apropriado, eficácia e custo-efetividade, da força de trabalho, de medicamentos, de equipamentos, de procedimentos e de práticas. Para este fim, eles devem possuir competências e habilidades para avaliar, sistematizar e decidir as condutas mais adequadas, baseadas em evidências científicas ${ }^{(10)}$.

A competência tomada de decisão esperada pelas supervisoras em questão está relacionada com a capacidade que elas têm em resolver problemas do cotidiano hospitalar, da profissão, da equipe, da equipe multidisciplinar ou até mesmo do cliente.

A partir da indagação sobre as contribuições do gerente de enfermagem das unidades funcionais para $\mathrm{o}$ desenvolvimento de competências dos enfermeiros subordinados, de acordo com a perspectiva destes, surgiram duas categorias temáticas: compromisso, motivação e facilidades para o desenvolvimento pessoal e profissional.

A categoria compromisso está muito ligada à ideia de estar disponível, de uma relação de ajuda. Elas entendem que a maior contribuição que podem oferecer para o desenvolvimento de competências nos enfermeiros é estar presente, ou seja, estar em contato direto com a equipe no dia a dia do trabalho e nas atividades diárias, bem como no apoio que oferecem a eles, como mostram as locuções a seguir:

Bom, nas atividades diárias sempre em contato diariamente com os enfermeiros. (S1)

Então eu acho que a forma com eu posso contribuir pra que as coisas aconteçam com mais eficiência, eficácia e efetividade é estando presente e aberta a ouvi-los e ajudá-los. (S2)

A minha maior contribuição eu acho, bem simplesmente, eu acho que é a minha presença constante. (S8)

Formalmente eu acho que não tenho contribuição nenhuma [...]. Talvez só informalmente pela maneira de conduzir o serviço, de ajudar a resolver as questões. (S6)

A supervisão não aparece como uma forma de controle do chefe com relação aos subordinados, pelo contrário, parece que as supervisoras são sensíveis aos problemas de seus subordinados de modo que buscam a resolutividade destes problemas, com os recursos institucionais que lhes são ofertados.

A atuação do enfermeiro em supervisão acontece por meio de instrumentos operativos utilizados com a intenção de otimizar as ações dos grupos em seu ambiente de trabalho. São estratégias que desenvolvem os indivíduos, propiciam o alcance de maturidade profissional e facilitam a participação destes indivíduos no processo decisório, promovendo interação harmoniosa, produtiva e satisfatória ${ }^{(16)}$.

Ainda considerando o questionamento sobre a contribuição do gerente para o desenvolvimento de competências surgiram respostas relacionadas à ideia de que, para contribuir com o desenvolvimento de competências, o gerente necessita motivar e facilitar. Notam-se os fatores motivação e facilitação nos discursos, respectivamente:

Diante da nossa realidade a gente tenta disponibilizar tempo pra essas pessoas poderem sair, fazer cursos fora [...]. Aquilo que não envolva recursos financeiros e sim, de uma dispensa do ambiente de trabalho, do turno de trabalho [...]. De um dia, dois, três, quatro [...]. Isso a gente pode fazer [...]. Basta ele ter interesse [...]. (S7)

Eu estou sempre incentivando, olhando para que busquem [...]. Incentivo a qualificação dos subordinados e também o fornecimento da estrutura pra isso acontecer. (S8)

A motivação pode ser conceituada como o desejo de se obter algo, ou um impulso para a satisfação profissional, o qual permite o crescimento e desenvolvimento organizacional, podendo, portanto ser utilizada pelos enfermeiros como uma estratégia gerencial da supervisão no desenvolvimento de competências, visto que canaliza e sustenta o comportamento das pessoas ${ }^{(17)}$.

Facilitar o desenvolvimento de competências significa propiciar aos enfermeiros condições para tal. Ou seja, o supervisor apropria-se de ferramentas gerenciais, como por exemplo, a reestruturação da escala de trabalho, planejamento da assistência de enfermagem, comunicação com seus pares, entre outras, para que os enfermeiros que constituem as equipes das unidades funcionais assistenciais consigam desenvolver, dentro e fora da instituição, suas competências profissionais. Isto traz reflexo positivo no cuidado de enfermagem, pois esta equipe será constituída de enfermeiros mais qualificados em sua prática. 
O modo pelo qual o gerente oferece contribuição para o desenvolvimento de competências na equipe se dá dentro das condições que a instituição oferece a ele, sem que isto signifique prejuízo para as partes envolvidas.

\section{CONCLUSÃO}

Considera-se que os objetivos do trabalho foram cumpridos e ressaltamos que isto não seria possível sem o uso da vinheta, que explicou o conceito de competências. As competências mais utilizadas pelas enfermeiras que ocupam os cargos de supervisoras demonstram maior ênfase no aspecto relacional (trabalho em equipe, comunicação, administração de conflito e liderança) da condução do trabalho em enfermagem. $\mathrm{O}$ uso destas competências evidencia o aumento da necessidade de articulação para a efetivação do trabalho em saúde, seja com a própria equipe de enfermagem, seja na sua relação com os outros membros da equipe multiprofissional.

Neste sentido, é importante salientar que esta complexidade se deve a diversidade de profissionais presentes nos hospitais de ensino, métodos de controle do trabalho (protocolos, sistemas de metas, pactuação com o gestor, e outros), o uso de tecnologias duras e a crescente interdependência entre os atores (profissionais, gestores e usuários) do sistema.

Em relação às competências esperadas por parte do supervisor de enfermagem dos enfermeiros a ele subordinados, a maioria também atendeu este aspecto relacional, o que evidencia que as articulações, para a efetivação do trabalho em saúde, não se restringem às supervisoras, mas também às enfermeiras, neste nível. Salientamos a competência técnica como sendo uma competência mais tradicional e esperada.

O desenvolvimento de competências gerenciais, principalmente no âmbito da saúde e em especial na enfermagem, é um grande desafio. Os resultados comprovam que a complexidade do contexto hospitalar na atenção à saúde dificulta o desenvolvimento de competências, principalmente com relação às estratégias, muito aquém das necessidades das enfermeiras, evidenciando que é preciso estimular o conhecimento acerca da temática neste contexto assistencial.

\section{REFERÊNCIAS}

1. Jorge MSB, Freitas CHA, Nobrega MFB, Queiroz MV. O Gerenciamento em enfermagem: um olhar crítico sobre o conhecimento produzido em periódicos brasileiros (2000-2004). Rev Bras Enferm. 2007;60(1):81-6.
2. Bernardino E, Felli VEA, Peres AM. Competências gerenciais para o gerenciamento em Enfermagem de hospitais. Cogitare enferm. 2010;15(2):349-53.

3. Nóbrega MFB, Matos MG, Silva LMS, Jorge MSB. Perfil gerencial de enfermeiros que atuam em um hospital público federal de ensino. Rev. enferm. UERJ. 2008;16(3):333-8.

4. Hospital de Clínicas. Assessoria de Planejamento. Coletânea sobre as unidades Funcionais da UFPR. Curitiba: HC/UFPR; 2002.

5. Gil AG. Como elaborar projetos de pesquisa. $3^{\mathrm{a}}$ ed. São Paulo: Atlas; 1999.

6. Galante AC, Aranha JA, Beraldo L, Pelá NTR. Vinheta como estratégia de coleta de dados de pesquisa em enfermagem. Rev. Latino-Am. Enfermagem. 2003;11(3):357-63.

7. Minayo MCS. O desafio do conhecimento: pesquisa qualitativa em saúde. $8^{a}$ ed. São Paulo: Hucitec; 2004.

8. Liberali J, Dall'Agnol CM. Supervisão de enfermagem: um instrumento de gestão. Rev. Gaúcha Enferm. 2008;29(2):276-82.

9. Corniani F, Galvão CM, Sawado NO. Liderança e comunicação: opinião dos enfermeiros responsáveis pelos serviços de enfermagem de um hospital governamental. Rev Esc Enferm USP. 2000;34(4):347-53.

10. Ministério da Educação (BR). Conselho Nacional de Educação. Resolução n. 3, de 7 de novembro de 2001. Diretrizes curriculares nacionais do curso de graduação em enfermagem. Diário Oficial [da] República Federativa do Brasil. 20019 Nov; Seção 1:37.

11. Farias LO, Vaitsman J. Interação e conflito entre categorias profissionais em organizações hospitalares públicas. Cad. Saúde Pública. 2002;8(5):1229-41.

12. Smith MH. Grievance procedures resolve conflict. Nursing Management. 2002;33(4):13.

13. Christovam BP, Santos I. Os desafios da gerência do enfermeiro no nível central de saúde. Rev. enferm. UERJ.2004;12(1):66-70.

14. Munari DB, Bezerra ALQ. Inclusão competência interpessoal na formação do enfermeiro como gestor. Rev Bras Enferm. 2004;57(4):484-6.

15. Jesus MS, Said FA. Autonomia e a prática assistencial do enfermeiro. Cogitare enferm. 2008;13(3):410-21. 
16. Servo MLS, Correia VS. Supervisão e a educação permanente da força de trabalho em enfermagem. Dialogos cienc. 2006;4(8):1-11.

17. Batista AAV, Vieira MJ, Cardoso NCS, Carvalho GRP. Fatores de motivação e insatisfação no trabalho do enfermeiro. Rev Esc Enferm USP. 2005;39(1):85-91. 